\title{
Using the flipped classroom to improve student engagement and to prepare graduates to meet maritime industry requirements: a focus on maritime education
}

\author{
Allison J. James • Christopher K. H. Chin • \\ Belinda R. Williams
}

Received: 2 July 2014 / Accepted: 11 September 2014 /Published online: 30 September 2014 (C) World Maritime University 2014

\begin{abstract}
This paper challenges maritime educators (MEs) to utilise the flipped or partially flipped classroom to meet increasingly diverse stakeholder needs. Given the international and geographically dispersed nature of the maritime industry (MI), the skills required are more complex than in a domestic situation. Further considerations include continuous improvement of learning and teaching practices whilst engaging with a unique student cohort, preparing a graduate suited to specific MI requirements and working within constrained university resources. At first, this may appear to be addressing too many divergent stakeholder expectations. The authors propose using backward course design (a design that meets the needs and goals of the specific nature of the MI through stakeholder consultation) as a premise to flipped teaching, thus unifying stakeholder requirements. Skills developed in the flipped classroom are particularly useful within the international nature of the MI. The skills required for effectively working in a linguistically and culturally diverse industry such as teamwork, decision-making, problem-solving and conflict resolution are practised in the flipped classroom. These skills along with specific consideration of MI-based cases and examples discussed in class time produce a more work-ready graduate attuned to specific industry requirements. This paper provides two application examples of the flipped classroom in the MI and highlights how this approach can lead to improved teaching outcomes for MEs.
\end{abstract}

\footnotetext{
A. J. James $(\bowtie) \cdot$ C. K. H. Chin

Australian Maritime College, Launceston, TAS, Australia

e-mail: a.james@amc.edu.au

C. K. H. Chin

e-mail: c.chin@amc.edu.au

B. R. Williams

Tasmanian School of Business and Economics, University of Tasmania, Launceston Campus, TAS, Australia

e-mail: belinda.williams@utas.edu.au
} 
Keywords Maritime education · Flipped classroom · Backward course design · Student engagement . Work readiness

\section{Introduction}

The need for improved teaching effectiveness and efficiency in higher education whilst addressing the needs of numerous stakeholders is a present quandary being addressed through the critical evaluation of current teaching strategies and classroom practice. In the maritime industry (MI), traditional classroom methods are applied to culturally and linguistically diverse and a more practical student cohort. Against this backdrop, employers are demanding graduates that are work or industry ready (graduates that can hit the ground running) (Pallis and $\mathrm{Ng}$ 2011) whilst universities are focused on student retention.

Mayer (2002) noted that meaningful learning occurs when students have the knowledge and cognitive processes needed for successful problem-solving. The practical nature of the MI presents maritime educators (MEs) with an opportunity to expect meaningful student learning that drives teaching practice. Focus should be on how students are learning, what they experience and how they engage in the learning context and subsequently meet graduate attributes which are considered vital by the MI (Wiggins and McTighe 2005; Progoulaki and Roe 2011). The flipped classroom promotes active student engagement and learning, in turn producing more industryready graduates (Strayer 2012; Hannafin et al. 1997; Bates and Galloway 2012; Mazur 2009). Through gradual facilitating of student-centred learning, MEs are turning their focus on graduate attributes in course/unit design and teaching.

The purpose of the paper is to extend the literature to showcase best practice techniques in helping to guide MEs towards consideration of the flipped teaching technique. This is actioned by examining two very diverse applications of the flipped classroom by MEs: one in maritime engineering and the other in maritime logistics management. The paper also discusses opportunities and challenges that are encountered in this teaching approach, providing solutions whilst seeking to improve the flipped teaching strategy.

The following section introduces the reader to the flipped classroom concept, followed by a discussion focused on backward course design, being the premise to flip teaching. Section 3 then applies the flipped and partially flipped classroom to two ME applications. Section 4 provides conclusions along with the opportunities and challenges to be considered when implementing flipped teaching.

\section{Literature review: the flipped classroom}

Flipped classroom teaching techniques are a pedagogical form of blended learning where the traditional classroom is flipped or inverted by delivering instruction outside the classroom and then bringing the application of learning outcomes into the teaching space. This approach is gaining in popularity shifting towards a more active student experience through "moving the lectures outside the classroom and using learning activities to move practice with concepts inside the classroom" (Strayer 2012, p. 171). 
The philosophy behind the flipped classroom teaching methodology is that it allows instructors to teach both content and process using a student-centred learning environment (Kim et al. 2014). This approach encourages active engagement by students in higher-order tasks and taking charge of their own learning (Hannafin et al. 1997). A typical flipped classroom approach provides students first exposure to the topic before class (through listening to pre-recorded instructions or lectures or completing prescribed readings) so that students are prepared to participate during class time in more interactive and higher-order activities such as problem-solving, analysing, discussion and debates (Kim et al. 2014; Walvoord and Anderson 1998; Davies et al. 2013; Fulton 2012; Mayer 2002).

This type of teaching is commonly thought of as a reversed teaching model, which is also referred to as an inverted classroom technique (Lage et al. 2000; Mason et al. 2013), or alternatively classroom flip (Baker 2000) where technology or resources are used to leverage, improve and create interest and learning. The result is that an instructor can spend more time interacting with students to apply the concepts and knowledge, instead of lecturing (Butt 2014). As noted by Bates and Galloway (2012, p. 8), "It is an exhilarating feeling to be freed from the tyranny of content coverage to be able to have the time and space to focus on what really matters... Furthermore, this understanding did not come with a price of 'covering' less material: we are convinced that, largely through the students' efforts outside class, we covered as much content but uncovered a great deal more understanding".

In comparison, the traditional teaching approach seeks to transfer information, as explained by Mazur (2009, p. 51): "I once heard somebody describe the lecture method as a process whereby the lecture notes of the instructor get transferred to the notebooks of the students without passing through the brains of either". In examining the flipped classroom approach, Pierce and Fox (2012) consider the flipped classroom as a reversal of roles where what used to be class work (namely, the instructor-led lecture and student note taking) is done prior to class, while what used to be homework (typically, assigned problems) is done in the scheduled class, thus turning the traditional information transfer approach upside down (Mazur 2009). Bishop and Verleger (2013) provide a survey of current and prior research into the flipped classroom approach with student perception results found to be consistently positive towards this approach.

In considering flipped learning studies, Ferreri and O'Connor (2013) redesigned a large lecture course into a small-group learning course. Results indicated that students preferred the smaller class formats and achieved significantly better academic grades. Bates and Galloway (2012) redesigned the curriculum in a large-enrolment introductory physics class to a flipped self-study approach by students prior to attending class and then a guided discussion session approach during class time. Results indicated significant learning gains by students and higher levels of engagement. However, one issue highlighted by this teaching approach was the mental shift that is required by academic staff to accept and embrace "an unstructured, contingent lecture experience in which the lecturer is no longer in complete control of" (Bates and Galloway 2012, p. 7). Bates and Galloway described the payoff for this approach as "the potential for an inclusive and participatory classroom atmosphere".

Other studies include that of Butt (2014) who, in conducting a flipped classroom approach in a final-year undergraduate actuarial course, found students became more receptive to this learning style as the teaching semester continued. Conversely, Strayer 
(2012) in comparing the learning environments of an inverted introductory statistics class with a traditional introductory statistics class found that students in the inverted classroom approach were less satisfied with how the classroom structure oriented them to the learning tasks in the course. However, they were found to be more open to cooperative learning and innovative teaching methods.

Some studies have considered the level of flippage required in a teaching environment. Alexander (2013) stated that flipping the classroom in one go might be too much, suggesting the idea of partially flipping and making some of the resources available online. An example of a teaching approach that utilised the partially flipped classroom concept was undertaken by Dawes and Fox (2013) in a grade 11 math course. They noted: "Our plan was to have our students watch a 15-20 minute video at home that would introduce the topic. Using the video lesson they (students) would complete introductory notes and work through one or two related problems. In the next day's class, we would have a short lesson to complete the topic and then give significant time to finish homework and ask questions; at this time we could also provide the one-to-one support that our students needed".

Dawes and Fox (2013) decided to partially flip the classroom to maintain some inclass math instruction, as students enjoyed and benefitted from this method of delivery. This approach of a partially flipped classroom, in which some resources are flipped but not all, may be a possible solution for educators that are yet to attempt the flipped classroom concept (Cold 2013). This is in keeping with Alexander's (2013) arguments, who described a creeping practice where, gradually, more resources can be flipped so that the fully flipped model can be used when and if it is deemed instructionally appropriate.

Class activities should focus upon a framework of higher level cognitive activities to inspire deeper learning. For example, problem-solving skills demonstrating application of logical, critical and creative thinking along with critical writing and analytical skills. These skills are not innate talents but can be learnt through instruction. The flipped classroom technique is an approach that fosters and facilitates deep student learning. Salmon (2004, p. 210) considered that "deeper learning is demonstrated by the...ability to explain a topic...to apply it and consider related theories. The deeper learner will also display more 'engagement' around the topic and the learning experience". By utilising this technique, the lecturer becomes the facilitator, while students are provided with increased opportunities to engage deeper and focus on industry relevant applied learning. For example, students who are undertaking a university unit in strategic management focussed on the maritime transport industry could undertake their conceptual or theoretical learning outside the classroom and apply the concepts by writing a strategic plan for a real MI organisation within the class time.

Mazur (2009) highlighted the learning gains achieved through utilising this approach, including detailed awareness of student's understanding and a higher-order learning occurring during class time. In applying this approach to the MI, the learning processes should focus on what occurs in the workplace and the specific characteristics of the MI. However, the literature is scarce on applying this learning technique to the MI. This paper thus seeks to extend the literature by showcasing best practice techniques in the MI. 


\subsection{The premise to flip teaching: backward course design in specialist industries}

Much of the literature on flipped classrooms is contextual, not specifically addressing the MI. Certain industries such as aviation, health care and banking require such unique skills that a specialist or contextualised approach is required. The international and geographically dispersed nature of the MI, coupled with multicultural and diversity complexities, presents a similar challenge for MEs.

Wiggins and McTighe (2005, p. 14) argue that an effective teaching tool that could be utilised to accommodate specialist industries is backward course design. Backward course design is a process of designing the educational curriculum by first identifying what the subject or unit learning outcomes are, identifying the skills that will demonstrate achievement of the learning outcomes and, finally, the content required to support these skills. In doing so, Wiggins and McTighe (2005) consider that it requires a major shift in the thinking of teachers and curriculum writers. This shift focuses on the need to consider the specific learnings sought and the evidence of such learnings, prior to considering how the teaching process will occur. This form of design takes the focus off the content-focused design and puts the focus on result-focused design (Daugherty 2006) and seeks to ask the question "what are students expected to know, understand, or be able to do after completing the course?" As an example of the use of backward course design, the CTE-Lilly Teaching fellows (2012, p. 1) note:

"Many courses are designed by first choosing a textbook or perhaps a collection of favorite activities, and using this to drive a sequence of presentation of course topics. However, if this knowledge transfer has only the vague goal of teaching the student to learn 'astronomy' or 'architecture', then the student is unlikely to walk away from the course with any understanding or competence in any authentic practice in the field". They also noted that "The instructor is no longer the 'sage on the stage', but rather, becomes a guide to the student learning process".

By following this approach, it is focused on teaching students to become life-long learners that can be applied in professional situations, thus lending itself to an approach that teaches authentic practice in the field. As Daugherty (2006, p. 5) noted "This model of design is standard-oriented instead of activity- or coverage-oriented because the teacher starts with what he/she wants the students to be able to do when the lesson has been completed rather than what material needs to be covered".

In essence, backward course design simply means consulting with various stakeholders and considering their needs in programme design (the structure of the degree) and individual units/subjects that comprise the degree. This extends to assessment tasks which can assist in producing a work-ready graduate. In particular, potential and current employers of our graduates must be consulted in design and assessment phases.

The MI is a complex, multicultural global industry (Progoulaki and Roe 2011). As Pallis and Ng (2011) highlight, the changing global environment has led to an increasing emphasis on professional, dedicated knowledge within maritime education. In view of such requirements, employees are required to respond effectively to ongoing change. Thus, the need for opportunity to learn and practise maritime skills in a teaching environment is paramount (Progoulaki and Roe 2011). From a MI perspective, 
by re-structuring the course using backward course design, this would allow the unique features of the MI to be explored. By understanding MI requirements and focusing on the end result first, students would then be able to see the relevance of what they are learning.

Further, by utilising this form of course design as a premise to flipped teaching, it would allow certain skill sets to be developed that are required at an international level. These include the need for cultural awareness skills and an understanding of the needs of diverse stakeholders which could be learnt through flipped teaching practices, as opposed to simply listening to a lecture. These skills, not just knowledge, are crucial to success, as are other key skills including, for example, the ability to perform and lead as part of a multinational team (Benton 2005; Berg et al. 2013). In addition, inter-cultural issues can be explored through flipped classroom techniques. For example, the skills and qualities that make an employee successful in one culture may be inappropriate in another.

Even for a MI employee who is employed in their home country, they would need to interact with teams, suppliers, partners and customers (stakeholders) in other countries. In turn, these organisation's teams and stakeholders are likely to be multicultural. The flipped classroom provides an excellent opportunity to practise and apply multicultural skills in a safe and encouraging environment. Communication and language skills can be observed and tried as students convey ideas effectively and efficiently both in written and oral communications as part of the flipped classroom activities. This is in contrast to simply reading about them or hearing the lecturer talk about them.

The MI is characterized by geographical and time dispersions which heightens the ability to work under pressure. Unforeseen cultural issues and trade barriers can arise. Whilst cultures help define ethnic groups as people share ideas, language and beliefs because they come from the same country, understanding cultural differences and attitudes to issues including gender, religion and social norms provides a framework for making important observations and about reactions to these observations. Individually and collectively, competitive advantage can be achieved by learning to meet impending deadlines quickly, using problem-solving skills and nurturing the ability to sense and evaluate new developments. These skills cannot be acquired from traditional teaching techniques such as reading a textbook or listening to a lecture with the mere transfer of knowledge no longer relevant in this dynamic environment.

\section{The flipped and partially flipped classroom: two ME applications}

In this section, two higher education academics working in ME provide application examples of the flipped and partially flipped approach. The examples are deliberately diverse to reflect the complex nature of MI and to demonstrate the possibilities in very different disciplines within ME.

\subsection{Application 1: maritime engineering-fully flipped}

Students enrolled in maritime engineering are required to complete mathematics during their first year of studies. Retaining their interest is crucial as students need to continually engage with mathematics over the duration of their programme. Recent 
studies by Freeman et al. (2014) raise questions about the continued use of traditional lecturing, instead supporting active learning as the preferred teaching practice to increase student performance. The use of hands on activities enables students to apply fundamental concepts and to use their knowledge and skills in further study and in industry. This is in agreement with Biggs's (2003) description of problem-based learning, in which students become very active and interact with their peers and learn necessary knowledge in applying to the problem in hand and developing selfmanagement and self-monitoring skills.

Maritime engineering students are provided with lecture notes at the commencement of the semester. To encourage students to attend the lecture, some of the printed examples in the notes are provided without solutions. In this way, the theoretical side is explained more easily which allows students to concentrate on listening and understanding, not on rote copying of materials. The printed examples are worked through immediately after explanation of the theory, and then, a series of blank examples are provided, which students attempt. At the end of each chapter of notes, there is a section of questions that students can attempt to practise what they have learnt in class. This set of bound lecture notes serve to replace the need for a standard textbook. Learning outcomes using Bloom's (1956) revised taxonomy of educational objectives are stated at the start of each chapter and address all the required objectives for student learning. This approach to teaching has been an adopted practise for a number of years and has worked extremely well, receiving positive feedback from both students and peers.

Students are asked to read through the theory and examples before attending the lecture and are provided with an activity worksheet of two to six problems before the class. During the fully flipped classroom, students are asked to form groups to discuss the problems in the worksheet. The academic works with the teams assisting them when required. These problems consist of mainly application problems where students need to apply the theory and concepts they have learnt before coming to class. An example is given in Fig. 1.

Once the class (consisting in excess of 100 students) have completed the problems, a randomly nominated student will then present his/her solutions in front of their peers whilst the rest of the class are encouraged to ask questions and critique the solution.

The figure on the right shows a one-kilometre-square city park located in Launceston. A local power company needs to run a power line from the north-west corner $A$ of the park to the southeast corner $B$. To preserve the beauty of the city park, only underground lines may be run through the park itself, but overhead lines are permissible along the boundary of the park. The power company plans to construct an overhead line a distance $x$ along the west edge of the park, then from the southern end of this line continue with a straight power line to point $B$. If overhead lines cost $\$ 50,000$ per kilometre and underground lines cost $\$ 120,000$ per kilometre, how should the power company construct the line to minimize its total cost? Use calculus to answer this question.

Fig. 1 An application problem during a flipped classroom

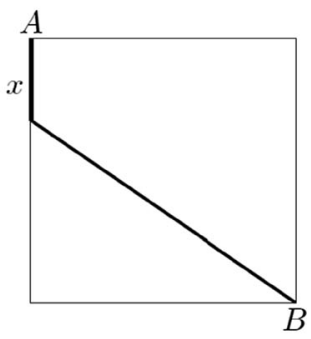


The lecturer then actively discusses the choice of methodology the student has used in solving the problem and corrects the solutions where required. At the end of the flipped classroom session, a set of solutions are handed out to the students for their reference. The flipped classroom materials are also uploaded onto the university's learning management system (LMS) with the entire session recorded and can be accessed by the students at any time.

In applying this application to a partially flipped classroom, the only difference would be students would be first taught the theory and its underlying concepts in a 50min lecture. In the next class (normally a 2-h class the following week), students would then be asked to form groups and to discuss the activity worksheet that was provided before class.

\subsection{Application 2: maritime logistics management-partially flipped}

The second application focuses on an undergraduate third-year maritime and logistics management course, called managing people for competitive advantage. The unit has a study package available in hard-copy format and on-line. The university provides a LMS, which is used as a platform upon which to provide unit content, asynchronous (takes place over time) discussion boards and a news system. In this example, asynchronous learning uses online resources to facilitate information sharing among students outside the constraints of time and place. This assists the facilitator to prepare the student before class and as an ongoing interactive communication system throughout the semester.

Students are provided with the following basic information at the commencement of the semester, describing the flipped approach and how the classes will be conducted:

You may have heard of the flipped classroom? It is also known as reverse instruction or flip teaching. This form of blended learning encompasses any use of technology or resources to leverage, improve and create interest and learning in a classroom. The result is that an instructor can spend more time interacting with students to apply the concepts and knowledge, instead of lecturing. In this style of classroom, the lecturer adopts the role of coach while students are provided with increased opportunities to engage in extended and applied learning. As such, we will have a concise interactive lecture followed by a workshop for the remainder of the class.

The lecturer will use $\mathrm{MyLO}^{1}$ to communicate and instruct, along with the study package. You will be assigned readings and activities to consider or complete before our workshops. What is required of you will be posted on MyLO well before the workshop date. Our small class environment ${ }^{2}$ facilitates an interactive style of teaching and learning that allows in-depth discussions, impromptu and informal verbal presentations which can build confidence and assist you to develop industry required skills in a relaxed, comfortable environment.

\footnotetext{
${ }^{1}$ Name of the on-line LMS

${ }^{2}$ On-campus class sizes are generally $30-40$.
} 
Before each class/workshop, students are designated a module to read which may include topic notes and short readings that are principally practitioner or MI centred. These real-world readings can then be used as a resource for answering workshop activities which are of a practical nature. Students are provided in advance (usually at the end of each class) the workshop activities sheet for the next class (this is also posted on the LMS) so the direction of the next workshop and the pre-reading is provided in a timely manner. For the first 30 to $40 \mathrm{~min}$ of each class, the lecturer conducts an interactive discussion based around the key concepts and readings. This serves the purpose of consolidating the theory and emphasising key concepts and terms. In a fully flipped classroom, the interactive lecture would not be included as students have the responsibility to study the content outside of the classroom, leaving class time for workshop application. The students then apply the concepts usually in teams or as part of a class activity structured around what actually happens in a corporate situation.

For example, if the topic is job analysis, students may practise the interview method of data gathering to prepare a job description. In the 2014 class, students had to write a job description for their lecturer. Students worked in teams to write a list of questions to interview the lecturer and then acted as a job analyst by asking the questions. The lecturer then discusses the choice of questions and the students can then see the immediate benefits/drawbacks of the types of questions asked. This knowledge can then be transferred to other types of interview questions. For example, asking closed questions that result in a yes/no answer did not acquire the information they neededthis knowledge was transferred and applied to the selection interview and the exit interview later in the semester. One can assume that as the concept is reinforced throughout the semester, it can then be transferred into the workplace, making a more work-ready graduate.

At each subsequent workshop, the theory/concepts learnt outside the classroom are applied to people management process. The lecturer is essentially a facilitator moving around the teams with approximately $80 \%$ of class time spent on working and engaging with students. Teams are regularly placed in the position of being on the management team and having to present their case as if in a meeting or boardroom or providing an elevator pitch.

These types of activities provide a different platform to comprehend and use the information experienced in a safe environment before facing the realities of the corporate world. Students that have been actively engaged in activities are more confident that they can actually apply what they have read about. Through this process, graduates are more work ready, particularly where case studies and articles are specific to the MI.

To further aid the ability to answer questions and incorporate the realities of the business environment, students are encouraged to bring your own device (BYOD). Students are welcomed to BYOD to work on class activities using their computers, tablets or smart phones. The students leave the classroom with information/knowledge and an understanding of how organisations actually undertake the concepts. Each student should be more assured that he or she can use and transfer these skills to the workplace.

Comparing this to the traditional lecture where the student goes away with pages of notes that one hopes might be relevant or useful. As with all teaching initiatives, this partial flip approach has to be weighed against the educators own 
judgment. One needs to choose the best teaching methods to communicate course content to the current group of students. Depending on future students, additional changes may need to be made to accommodate their needs, such is the continual challenge educators are faced with.

\subsubsection{Maritime logistics management: preliminary evidence of learning}

To gauge the success of this teaching approach and as part of continuous improvement, student feedback was sought on the partially flipped teaching approach through an endof-semester survey conducted in class time. Students were asked if the flipped classroom activity is more engaging than traditional lecture instruction. Typical comments that were provided included "this teaching approach makes me come to class every week", "students are involved throughout the whole lecture!", "class discussion is great" and "I am getting more confident".

\section{Discussion and conclusion}

We consider that the flipped classroom is a pedagogical model in which the typical lecture and homework elements are reversed. Many earlier definitions of a flipped classroom suggest the use of videos or multimedia materials viewed before an in-class learning activity. Other authors maintain a much broader approach. We extend our definition to the use of any other medium or resources (some of which are discussed in the ME applications) and/or the use of a LMS to communicate and provide content, support and material.

The context and elements of the MI in many aspects differ from more traditional professions. We argue that the distinctive nature of the working environment not only leads to specific graduate attributes but also requires a practical, flexible and dynamic teaching approach achieved through the flipped classroom and MI consultation. Flipped teaching techniques provide the MI with key opportunities in preparing students towards a more work-ready graduate attuned to specific industry requirements. These include the following opportunities:

- Students systematically are taught critical thinking. Subsequently, students ask questions of the facilitator and other students when working in the team activities which provide immediate feedback on their learning and therefore benefitting from both their successes and mistakes. This back and forth conversation between the facilitator and the student/s is in stark contrast to being lectured to.

- Active learning which is inherent in flip teaching provides a platform upon which to rehearse subject content and practice work and industry skills. Independence in thinking and action learnt in the classroom can be transferred and applied to the work environment.

- Less effective students are exposed to the learning processes of effective learners, thus encouraging engagement and learning from each other. This creates a forum for sharing learning approaches and ideas. 
- More effective learners can see how they may assist in a mentoring/teaching capacity. This skill can be transferred to the corporate and work environment after graduation.

- Supports and facilitates active student-centred learning and can enable multiple learning styles.

- Opportunities are generated for students to explore their own propositions, promoting practices consistent with skill development as life-long learners.

- Targets the development of the skills of independent study (self-directed learner) which prepares for life-long learning and skills required in the international context in which the MI operates.

- Provides sequential opportunities to reinforce and apply knowledge. Students can question what is happening, can seek clarification on what they do not understand and project ideas forward into similar work and unique MI situations. Peer-to-peer-centred learning builds skills in managing conflict, creativity, time management and collaboration. Opportunities to improve team building and problem-solving skills produce an immediate, timely outcome. Leadership skills are demonstrated and developed.

- Students are learning to think critically. Their questions can be more analytical as they have had time to contemplate the material before class.

Through our experiences and study of the flip teaching method, we also note the following challenges:

- The approach may not suit traditional learning styles of culturally and linguistically diverse MI students. This is normally overcome as students become familiar with the approach and progressively come on board (see student comments and in Section 3.2.1)

- Academics require technology competence. Before commencing, the flip approach consideration is required on personal competence and the quality and quantity of the technology support provided by the teaching institution.

- The actual physical layout of the classroom requires consideration. For example, room size, layout and availability of desks that can be moved to provide space for separate team discussions and the ability to project team answers as in a boardroom situation may be required for managerial type answers.

- By considering the graduate attributes required, course and unit designers need to engage more with the MI and employers. The MI is addressing a well-known skills shortage (Industry Contributors 2008), along with the employer challenges of attracting and retaining staff. Employers are aware that graduates can play central roles in their organisation's transformation, improving business processes and customer service through new insights. By employers being part of the instructional design process, a more industry-ready employee is likely.

- The function of the employer moves to an active role in course and unit design. Employer consultation should be considered in the evaluation stage of the flipped teaching cycle. We would consider this to be an opportunity but recognise that it could present a challenge in some teaching environments.

- Creating a flipped classroom requires significant time invested initially to construct learning activities for the classroom and to develop resources to be consumed before the class. We argue that the time investment is paid back once these resources are created and revised. 
- Not all students are self-motivated. Some students do not do the readings before the class. This might lead to less participation and engagement from this group of students. A significant barrier is students who do not prepare for sessions fall behind and may struggle. Therefore, it is important that the lecturer encourages students to do the work before the flipped class.

- Some see the concept of flipped classroom as more homework for students leading to extra workload. However, with the introduction of flipped classroom, the lecturer can assign less homework than in the past. Some lecturers pre-prepare their lectures and upload them onto the university's LMS. This has several advantages such as the students can listen to the recordings at the location and time most convenient to them. However, there is an expectation that students do listen to the recordings and come to the class prepared. It cannot be assumed that all students have a computer (or tablet) and internet access at home and those students that are at sea may have intermittent internet access. Also, students from low-social economic background may be unable to afford these resources.

One should not make a quick decision to introduce the fully flipped classroom. For those who are uncomfortable with the idea, perhaps a partially flipped classroom would initially be ideal. For example, a 15-min introduction before the actual flipped classroom could also reinforce some ideas. Ideally, a flipped classroom should be a 2-h session to allow time for students to discuss their ideas and present their answers before the lecturer steps in to discuss the results. Though there is some work involved in the preparation, which means extra workload for the lecturer, the result is worthwhile. Everything should be done in moderation.

Changes in the MI and higher education require the transition to the workforce and are reflected in the design and implementation of degree courses and individual units. This requires MEs to consult with the MI to merge the practical with academic discipline requirements. Flipped teaching techniques could be employed to transition students between the university and the workplace. MEs need to prepare students for employment through non-traditional learning strategies and opportunities. The authors envisage a new edge in MI education with opportunities for teaching strategies that will energise the student and produce graduates with desirable MI attributes. Flipped teaching could provide this edge; however, more application of this form of teaching is required in the MI, allowing for future research opportunities examining skill development, levels of engagement and application to the work environment. Further, empirical research is required that provides evidence of the success of the flipped classroom versus traditional classroom teaching techniques. This could include, for example, a comparison of examination results taken from the two pedagogical environments in the MI setting.

\section{References}

Alexander A (2013) Planning your flipped classroom. http://moodle.oakland.k12.mi.us/os/mod/assign/view. php?id=60659. Accessed 27 May 2014

Baker JW (2000) The classroom flip: using web course management tools to become the guide by the side. In: Chambers JA (ed) Selected papers from the 11th international conference on college teaching and learning. Florida Community College, Jacksonville, pp 9-17 
Bates SP, Galloway RK (2012) The inverted classroom in a large enrolment introductory physics course: a case study. Proc HEA STEM Learn Teach Conf. doi:10.11120/stem.hea.2012.071

Benton G (2005) Multicultural crews and the culture of globilization. Presented at the International Association of Maritime Universities (IAMU) 6th annual general assembly and conference, Sweden

Berg N, Storgard J, Lappalainen J (2013) The impact of ship crews on safety. Centre for Maritime Studies, University of Turku

Biggs J (2003) Teaching for quality learning at university, 2nd edn. Open University Press, USA

Bishop JL, Verleger MA (2013) The flipped classroom: a survey of the research. Proceedings of the 120th American Society of Engineering Education Annual Conference and Exposition, Atlanta

Bloom BS (1956) Taxonomy of educational objectives, handbook I: the cognitive domain. David McKay Co., Inc., New York

Butt A (2014) Student views on the use of a flipped classroom approach: evidence from Australia. Bus Educ Accred 6(1):33-43

Cold SJ (2013) Partially flipped: experiences using POGIL. Proceedings of the SIGITE Conference, RIIT 133-134

CTE-Lilly Teaching fellows (2012) Backward design approach to curriculum design. Office of undergraduate studies, supporting document for scholarship in practice, the University of Maryland. www.gened.umd. edu/documents/BackwardDesign.pdf

Daugherty KD (2006) Backward course design: making the end the beginning. Am J Pharm Educ 70(6):1-5

Davies RS, Dean D, Ball N (2013) Flipping the classroom and instructional technology integration in a college-level information systems spreadsheet course. Educ Technol Res Dev 61(4):563-580

Dawes K, Fox M (2013) The partially flipped classroom. Indep Teach Mag 11(1)

Ferreri SPP, O'Connor SKP (2013) Redesign of a large lecture course into a small-group learning course. Am J Pharm Educ 77(1):1-13

Freeman S, Eddy SL, McDonough M, Smith MK, Okoroafor N, Jordt H, Wenderoth MP (2014) Active learning increases student performance in science, engineering, and mathematics. Proceedings of the National Academy of Sciences of the United States of America http://www.pnas.org/content/early/2014/ $05 / 08 / 1319030111$

Fulton K (2012) Upside down and inside out: flip your classroom to improve student learning. Learn Lead Technol 39(8):12-17

Hannafin M, Hill J, Land S (1997) Student-centred learning and interactive multimedia: status, issues and implication. Contemp Educ 68(2):94-99

Industry Contributors (2008) Moving business forward: Australian expertise in transport and logistics. Focus Publishing Interactive, pp 140-161

Kim MK, Kim SM, Khera O, Getman J (2014) The experience of three flipped classrooms in an urban university: an exploration of design principles. Internet High Educ 22:37-50

Lage MJ, Platt GJ, Treglia M (2000) Inverting the classroom: a gateway to creating an inclusive learning environment. J Econ Educ 31(1):30-43

Mason G, Shuman TR, Cook KE (2013) Inverting (flipping) classrooms - advantages and challenges. Proceedings of the 120th ASEE annual conference and exposition, Atlanta

Mayer RE (2002) Rote versus meaningful learning. Theory Pract 41(4):226-232

Mazur E (2009) Farewell, lecture? Science 323(5910):50-51

Pallis AA, Ng AKY (2011) Pursuing maritime education: an empirical study of students' profiles, motivations and expectations, Maritime Policy \& Management: The flagship journal of international shipping and port research, 38:4, 369-393

Pierce R, Fox J (2012) Vodcasts and active-learning exercises in a "flipped classroom" model of a renal pharmacotherapy module. Am J Pharm Educ 76(10):1-196

Progoulaki M, Roe M (2011) Dealing with multicultural human resources in a socially responsible manner: a focus on the maritime industry. WMU J Marit Aff 10:7-23

Salmon G (2004) E-Tivities: the key to active online learning. Kogan Page, London

Strayer JF (2012) How learning in an inverted classroom influences cooperation, innovation and task orientation. Learn Environ Res 15:171-193

Walvoord BE, Anderson VJ (1998) Effective grading: a tool for learning and assessment. Jossey-Bass, San Francisco

Wiggins G, McTighe J (2005) Understanding by design. ASCD, Alexandria 